\title{
DESIGNING THE EDUCATIVE APP FOR THE DETERMINATION OF TYPICAL SLOVENIA ROCKS
}

\author{
Anja Škerjanc ${ }^{1}$, Tadej Abram ${ }^{1}$, Aja Knific Košir ${ }^{1}$, Rok Brajković ${ }^{2}$, \\ Žiga Fon ${ }^{3}$, Petra Žvab Rožič ${ }^{4}$, Helena Gabrijelčič Tomc ${ }^{1}$ (iD \\ ${ }^{1}$ University of Ljubljana, Faculty of Natural Sciences and Engineering, \\ Department of Textiles, Graphic Arts and Design, Ljubljana, Slovenia \\ ${ }^{2}$ Geological Institution of Slovenia, Dimičeva Street 14, 1000 Ljubljana, Slovenia \\ ${ }^{3}$ Digied, e-learning development and production company, d.o.o., Žirovnica, Slovenia \\ ${ }^{4}$ University of Ljubljana, Faculty of Natural Sciences and Engineering, \\ Department of Geology, Ljubljana, Slovenia
}

\begin{abstract}
Applications presenting the content of a specific professional field are more frequently used for educational purposes. Not only that the interactive solutions including multimedia can more effectively transfer knowledge due to their property to offer a content on a demand, but they are also very attractive, they augment user experience, are able to present more spatial and time dependent data and they usually involve multisensory approaches including senses of vision, hearing and touching.

In the research the work frame and a design process of the educative app solution for geological purposes is presented. The aim of the app is to interactively determine stones by means to implement geological stone key. The experimental part presents the strategy phase, in which the target groups were defined, their needs were analysed and touching points for the successful networking, sharing and promotion were introduced. Next, app's functionalities and content types were created, based on the specification of professional field of geology. The content was categorised and labelled so that in the context of the whole app's structure required hierarchy and organisation of the content categories were introduced. User interface design began with simple layout sketches and with iterative approach that followed, more interactive prototypes were designed, developed and tested using the wireframes. In the results the final prototype and its design are presented with the evaluation of user-centred design approach that was implemented in the work frame.
\end{abstract}

Key words: stone key, user interface, design process, educative app, geology

\section{INTRODUCTION}

Interactivity is a potencial of action-reaction between different communication units (human - computer interaction). It is also a communication process and a dialog that considerably improve the effectiviness of education when it is applied in educative content (Jakupović, 2018). On technological level, multimedia interactive content are persistently gaining the popularity and the applicative value in new media. As was demostrated, effectiveness of educational content and the quality of working memory is improved when the content is percieved (seen, heard and touched) and sensed (experienced) interactively and as such prompt the user to act, colaborate and continusly self-evaluate the understanding and knowledge (Rias \& Zaman, 2010). Nowadays trends of the known and respected universities is to offer without any costs and with open-access web workshops, seminars and other forms of educational activities, mentor support and effective evaluation of the knowledge (Mlakar \& Štepic, 2018; Youngs, 2018).

When interactivity and multimedia in the learning process is discussed, the science of education should be considered and the Mayer's cognitive theory breafly introduced. Mayer's researches include theories of learning process, congitive physhology and media technology. In the book about the multimedia in the education he presents the discoverings that the study content including only images or only text is less efficient as content including the combination of both content type. This principle of production of educative content, named also a principle of multimedia, is conected to the Mayer's theory of learning with multimedia and is a foundamental guide in multimedia design. The theory behind the principle of multimedia states that human being has two channels for information processing, that the working memory is limited and that a efficient learning is possible only when the student is cognitively active (Mayer, 2014).

Planning, production and development of interactive media are usually performed with two simultaneous processes that include the creator - the designer and the consumer - the user of the application. The designer is involved in the creative process of planning, designing and producing the media and implements 
the methodologies of user-centred design that offer the augmentation of users' experience when consuming the media. The designer's work is a multi-layered process that usually include five elements of designing user experience - UX (Garret, 2011): 1. the strategy plane; 2. the scope plane; 3. the skeleton plane; 4. navigation and interface design and 5. surface level and sensory design. In the strategy plane the needs of the app's users and app's objectives are analysed, introduced and transpose in the concept of interactive media. In the second, scope phase the app's functionalities (interactive map, searching, etc.) and types of content (images, text, video) are be defined and categorised, the relevant touch points (social media) are defined and the strategy of communication through touch points is elaborated. In the third and fourth phase organisation, hierarchy, labelling and internal structure and skeleton of the app (information architecture) is established and navigation design is performed. With the start already in the fourth phase, interface design continues in the fifth, last phase of UX design, i.e. the app's surface level and sensory design.

When developing and designing of educative mobile application some important features should be included in the process and solution. The app's databases should be powerful and stable enough to support different functionalities (uploading new content, sharing etc.) and various type of multimedia content should be planned and created with the focus of successfully persuade all the target groups. As the interactive communication is more effective, when there is a direct and "personal" contact between the communicative units, the app should include virtual tutors or at least video or animated interactive tutorials. It is recommended that in the app there is a functionality of a self-evaluation process that should be effectively included on different learning levels. The basic functionalities (login, statistics etc.) should be designed according to the principles of user-centred design that had to be implemented also in the user interface design process. Further, features of personalisation are indispensable and can be developed directly from the profiled analysis of target groups and personas. These features should be planned and included as smart interactive elements and not as abusive additives (Still \& Crane, 2016).

User-centred design is crucial in the educative apps' development, when in the framework of working phases special attention is given to the users, their cognitive processes, the environment of the use of the product (media), usability goals and especially the context of the media consumption. Here, user-centred design is a problem-solving multi-stage process which aim is the testing and the analysis of users' behaviour, experience and immersion when human-media interaction occurs. Besides, the evaluation of the usability and user experience is performed iteratively and in many consecutive phases of the product development, design, production and its actual use (William Albert \& Tullis, 2013).

In this research we present the work frame and a design process of the educative app solution for geological purposes. The aim of the app is to interactively determine stones by means to implement geological key. The educative part of the solution includes step by step process of recognition and labelling of stones that can be found in Slovenian region. Consequently, the focus during the app's user interface and content development was the implementation of user-centred design that considered users' cognitive processes of understanding, learning and memory to achieve knowledge about the different stones' name, properties and origin, and consequently their geologic category.

\section{EXPERIMENTAL}

In the research work, professionals from three main research fields were included, i.e. geologists, graphic designers and programmers, which members were students and mentors. The work was directed by the creative director of the company Digied that covers the development and implementations of advanced user-oriented solutions for ICT supported education. In this contribution and its experimental part, we focus on designing the educative app that included the following phases:

- $\quad$ strategy phase;

- $\quad$ prototyping and wire frame design;

- graphic identity design;

- creation of functionalities and content;

- navigation and interface design;

- testing and design redefining;

- $\quad$ promotion of the project and educative application.

In the strategy phase, the timeline of the research work was carefully defined with the consideration of the goals and complexity of the tasks included in the work. While the geologists were developing the geological 
key (defining three main groups of Slovenia stones: magmatic, metamorphic and sediment stones), i.e. the systematisation of labelling and categorisation of Slovenian stones, the target groups and their needs were defined and analysed by the graphic designers. Touch points for the successful networking, sharing and promotion were introduced and were active (for promotion, tracking of project working phases) already during the project work. The development of the information architecture started already in this first, strategy phase of the project (Figure 1).

Prototyping and wire frame design began with simple sketches and with iterative approach 4 stages of prototype were designed and tested (Figure 1). Each iteration was an upgrade of the previous version and all findings from the intermediate quick testing from the on defined prototype were implemented in the next version.

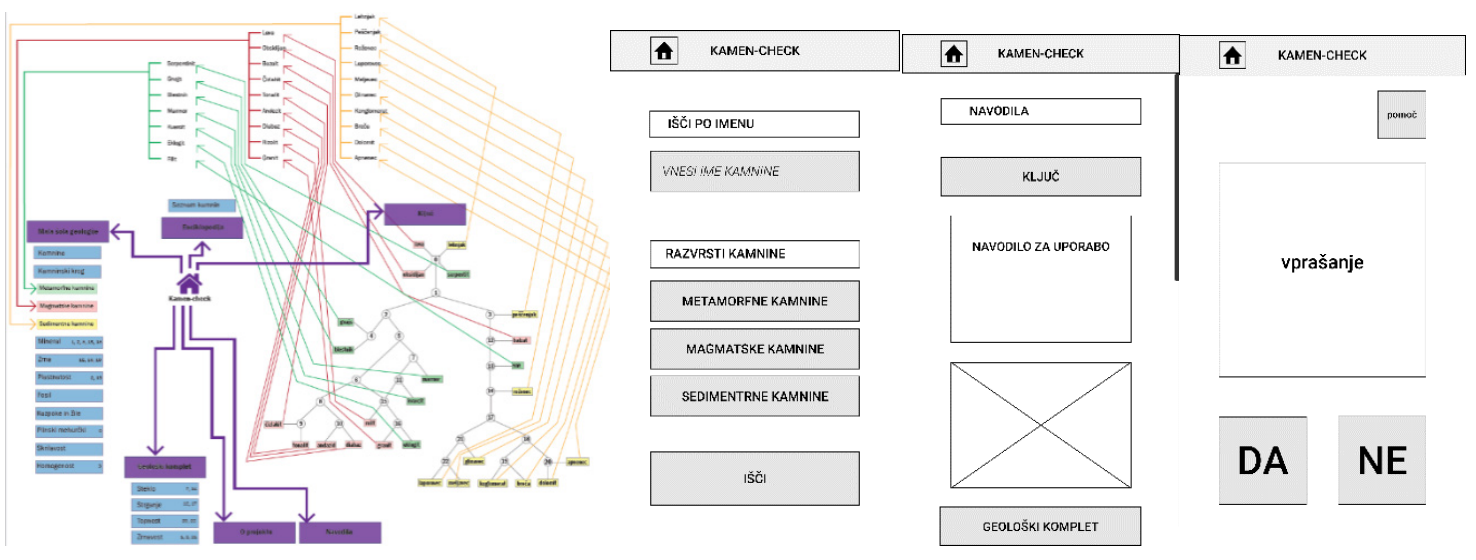

Figure 1: Information architecture, i.e. the structure, hierarchy and labelling of educative app and static prototype and wireframes

Graphic identity design originated from the main content elements of the interactive solution, i.e. stone. Graphic identity was determined with the logotype, selection of the colour pallet and font types. The symbol of the logotype, i.e. symbol of stone, was designed as a multi-sided geometrical object and the text part included a creative name of the application KamenCheck that means StoneCheck. A logotype version and selected fonts are presented in Figure 2.
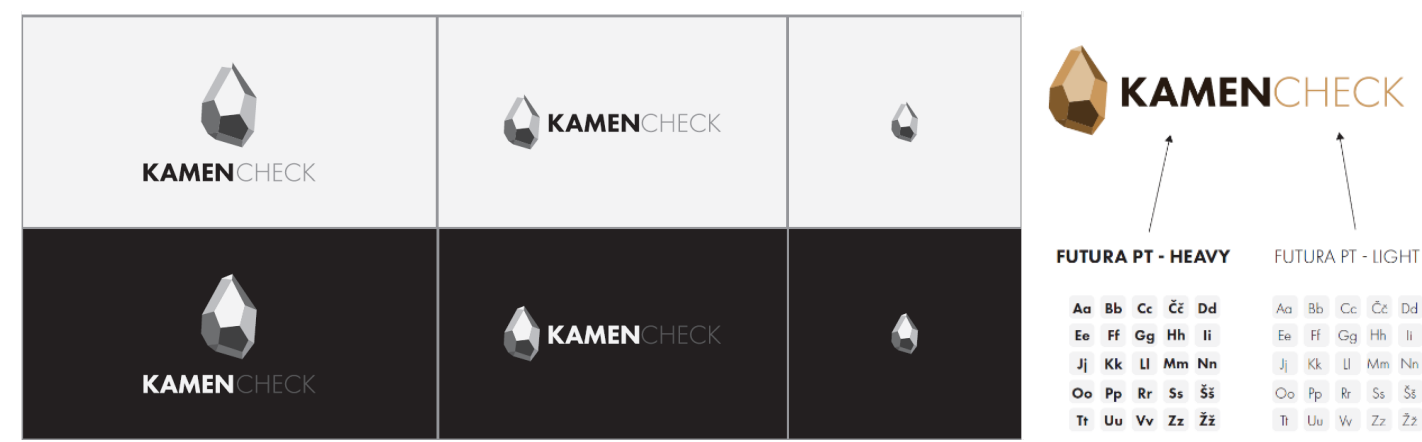

Figure 2: Elements of graphic identity and logotype

Next, app's functionalities and content types were created (photos, videos, 3D models, illustrations, text), based on the specification of professional field of geology. The photos of the selected stones were acquired in photo studio and beside regular photography also 360 records were performed. The letter was planned to be implemented in 360 video presentations of the stones and to be used as a photogrammetric records for additional AR interactive presentations of stones. The content was categorised and labelled so that in the context of the whole app's structure a successful hierarchy, organisation and categorisation were introduced. In Figure 3 shots from instructional video, explanatory photos and educative illustrations are presented. 


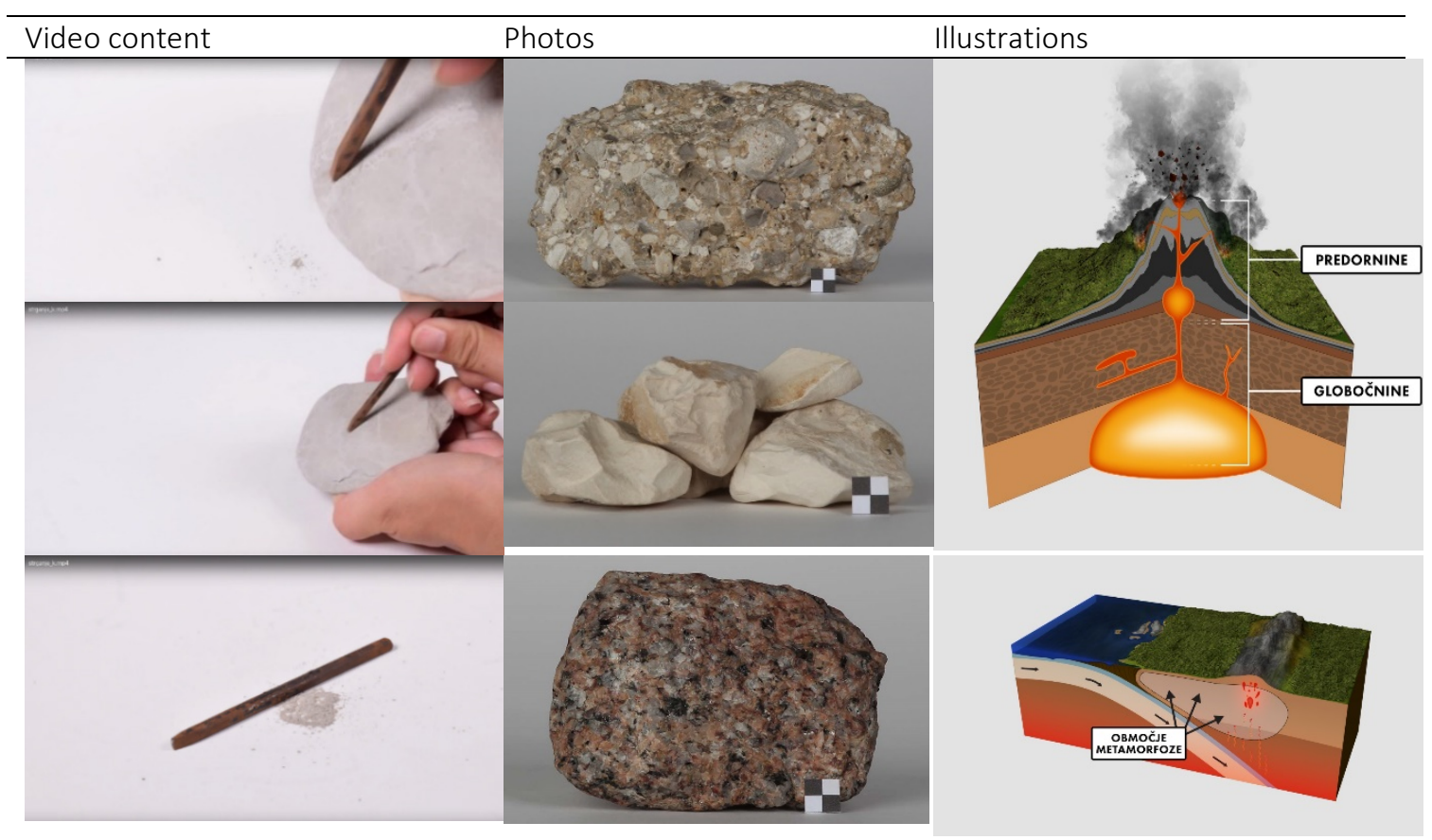

Figure 3: Presentation of the video shots about the checking and defining the stone group (category), photos of the stones with the unit measurement and educative illustrations of geological process

Navigation and interface design was carefully planned and implemented considering the structure and the hierarchy of the content categories. Ikons, buttons and other static and interactive elements were designed according to the principles and concepts of Material design, which guidelines were used also for the design of the layout, i.e. composition and arrangements of the graphic elements of the user interface. Moreover, the user interface design implemented also some of the state of the art principles of human perception and the findings of our intermediate usability testing.

Testing of the wireframes and prototypes was performed on a smaller number of users (No. $=5$ ) with the focus of discovering issues, errors, inconsistencies and non-uniformity.

Usability testing implemented performance metrics, i.e. the representative users were asked to freely use an educative application, while the developers observed users' performance and recorded the usability issues. After each testing, the design was iteratively redefined.

Promotion of the project and started already in the initial phase of the project with the development of effective communicative channels (social media and project's web site) so that in the project team the connective and collaborative atmosphere was created. After the communication was established internally, the promotion continued and is still in progress externally through target promotional activities on social media, contributions on symposiums and meetings, etc.

\section{RESULTS AND DISCUSSION}

The workflow of the project was strongly imprinted by the creative design thinking methodologies and the results is a quality, functional educative application with the geological content. Phases of emphasizing, defining, ideating, prototyping and testing were iteratively and interchangeably included through a multi-layer process of the elaboration of a stone key and were implemented in a user-oriented interactive application with an attractive user interface and stylish colours, iconography, graphic elements and typography.

In the strategy phase three main target groups were defined, primary - middle school's teachers and pupils and elementary pupils between 10 and 13 years; secondary group: geoparks, elementary pupils, geological museums and persons interested in the field. The tertiary target group included the clients from the Institute for education and the financers of the project. The content (photos, videos, illustrations and graphics) was produced with the high communicative value considering the geological specifications and the context of the user-oriented interface as is presented in Figure 4. 
The approach of user-centred design was successful, resulting in educative didactic tool. In further researches, the usability testing is going to be performed at the elementary and middle schools and some improvements of the app's functionalities are going to be implemented (presentations of augmented reality of stones).

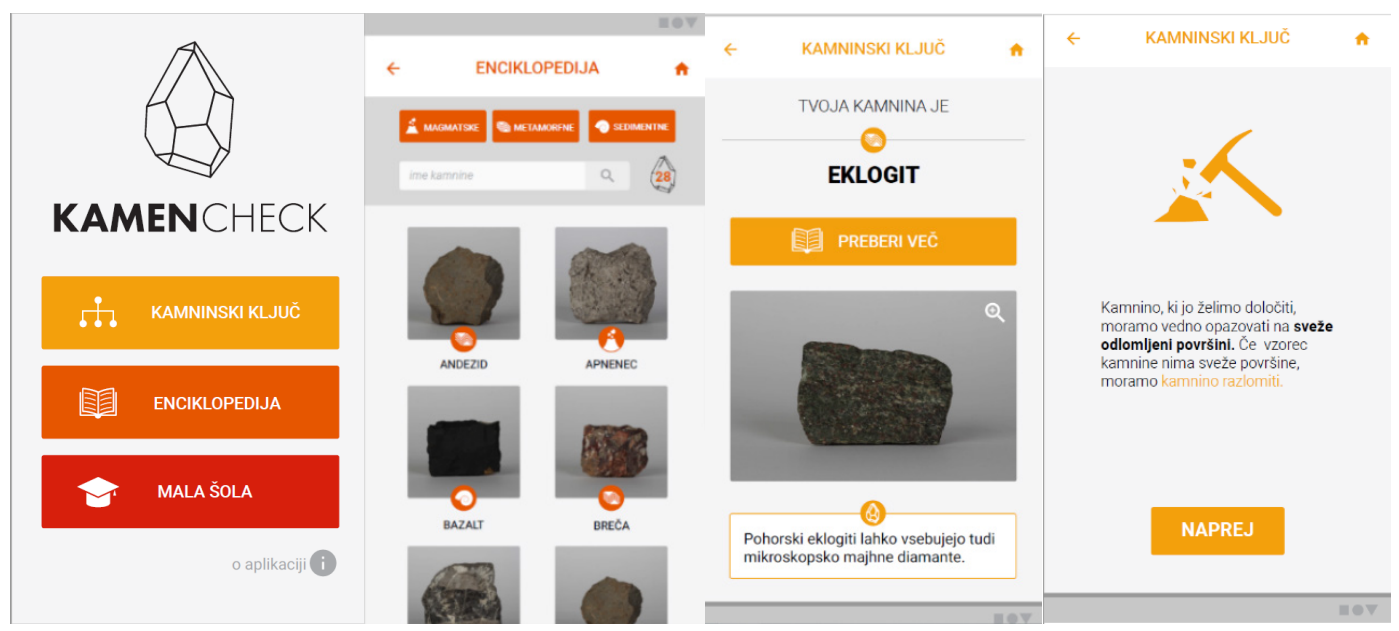

Figure 4: Final design of the educative app Kamencheck

In Figure 5 activities on social networks are presented that were the integral part of app's promotion strategy. Each step of the project work and the results were published and presented with the optimised web content and attractive visual communications, which aim was to introduce an educative application KamenCheck to the target groups and generate its exposure on the web. Beside the digital promotion also posters, leaflet and T-shirts were designed as is presented in Figure 5.

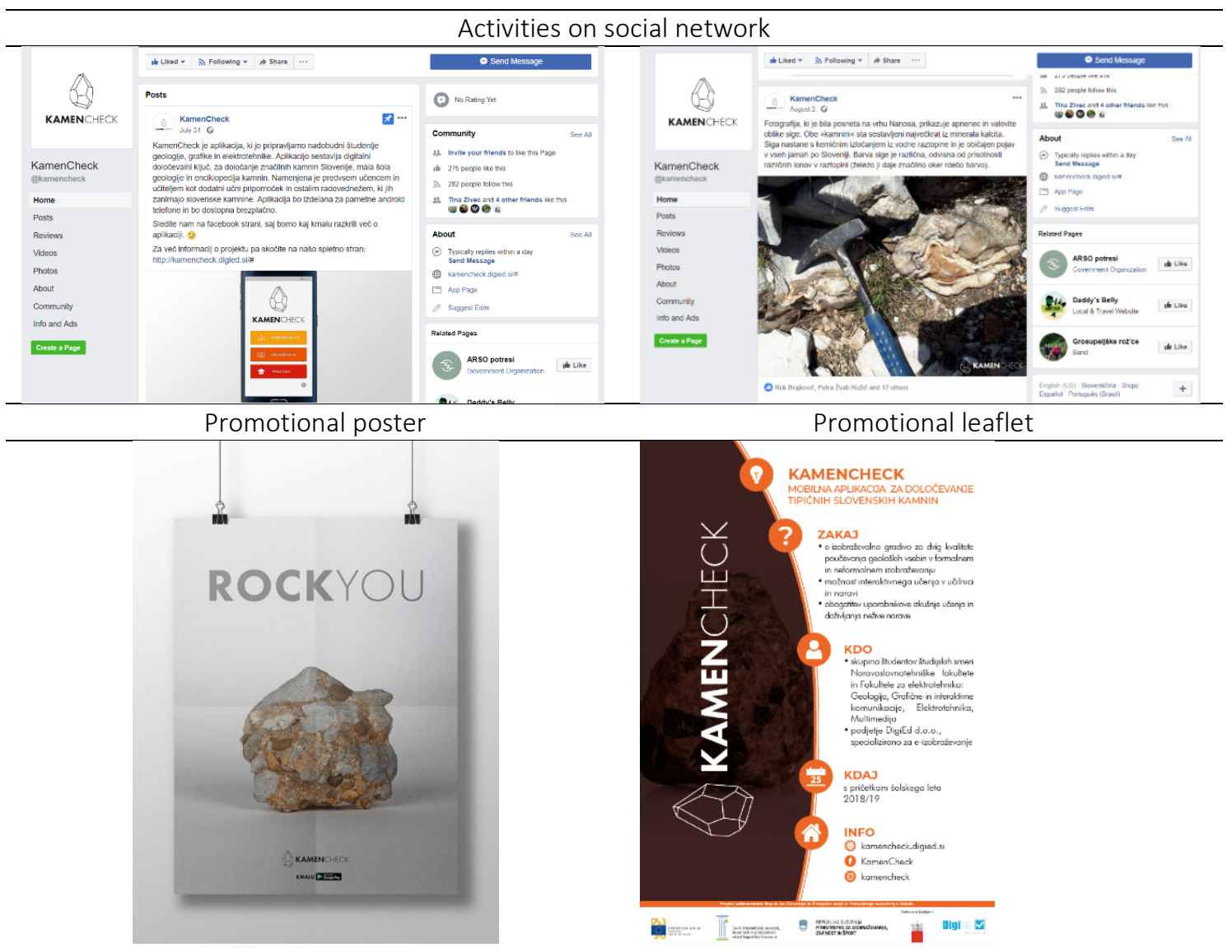

Figure 5: Activities on social network, promotional posters and leaflet 


\section{CONCLUSIONS}

User centred design is an effective methodology that in our project resulted in successful design of educative app with the geological content. The evaluation of the app's interface, content design and usability discovered that the interactive solution is highly functional with a very good user experience and perfective design. The goals of the project were achieved, however, the results of user experience evaluation discovered that some functionalities could be improved, and that the usability of the app could be upgrade with AR presentation of stones that certainly could reinforce the educative effects and attractiveness of the solutions. 3D technologies (photogrammetry, scanning and 3D modelling) were indeed applied in the workflow, however the 3D model and texture optimisation and the reduction of topology details in the 3D stones' representations for the real-time presentations are complex procedures and consequently are still in the researching phase.

\section{ACKNOWLEDGEMENTS}

The project was financed by the Public Scholarship, Development, Disability and Maintenance Fund of the Republic of Slovenia, Ministry of Education, Science and Sport (Republic of Slovenia) and European Social Fund and was a part of Public tender project work with the economy and the non-economy in the local and regional environment - creative way to the knowledge 2017-2020. The authors of the contribution would like to thank the supporters of this project and all the dedicated participants involved.

\section{REFERENCES}

[1] Garret, J. J.: "The Elements of User Experience: User-Centered Design for the Web and Beyond", $2^{\text {nd }}$ ed, (New Riders, Berkeley, 2010).

[2] Jakupović, E.: "V izobraževanju so čedalje bolj priljubljene multimedijske interaktivne vsebine", Ikt.finance, URL: https://ikt.finance.si/8848337?cctest\& (last request: 2018-08-27).

[3] Mayer, R. E.: "The Cambridge Handbook of Multimedia Learning", $2^{\text {nd }}$ ed, (Cambridge University Press, New York, 2014). doi: 10.1017/CBO9781139547369

[4] Mlakar, A., Štepic, M.: "Programi za animacijo". URL: http://upomancaandrej.weebly.com/programiza-animacijo.html (last request: 2018-08-27).

[5] Rias, R. M., Zaman, H. B.: "Learning with Multimedia: Effects of Different Modes of Instruction and Animation on Student Understanding", Jurnal Teknologi Maklumat \& Multimedia 9, 57-70, 2010.

[6] Still, B., Crane, K.: "Fundamentals of User-Centered Design: A Practical Approach", (CRC Press, Boca Raton, 2016).

[7] Tullis, T., Albert, W.: "Measuring the User Experience, Second Edition: Collecting, Analyzing, and Presenting Usability Metrics", $2^{\text {nd }}$ ed, (Morgan Kaufmann, Burlington, 2013).

[8] Youngs, K.: "How to use 3D content in simulations for teaching and learning", Jisc.ac, URL: https://www.jisc.ac.uk/blog/3d-in-teaching-and-learning-23-sep-2014 (last request: 2018-09-10).

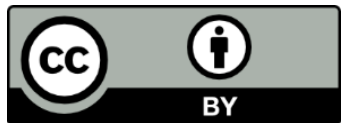

(C) 2018 Authors. Published by the University of Novi Sad, Faculty of Technical Sciences, Department of Graphic Engineering and Design. This article is an open access article distributed under the terms and conditions of the Creative Commons Attribution license 3.0 Serbia

(http://creativecommons.org/licenses/by/3.0/rs/). 